\title{
ENTREVISTA
}

\section{Poder e resistência na história de Portugal: do antigo regime à Primeira República - Observações historiográficas de António Manuel Hespanha e Ernesto Castro Leal}

Power and resistance in the history of Portugal: from the old regime to the First Republic

- Historiographical observations of António Manuel Hespanha and Ernesto Castro Leal

Poder y resistencia en la historia de Portugal: del antiguo régimen a la Primera República - Observaciones historiográficas de António Manuel Hespanha y Ernesto Castro Leal

José Pedro Zúquete*

As resistências aos poderes vigentes nunca nascem no vazio, mas pertencem a uma genealogia, inscrevem-se numa sucessão de períodos e episódios de mobilização e ativismo, que se sucederam ao longo dos tempos, cruzando vários regimes políticos. Daí a importância de ter uma visão temporal e histórica sobre estes fenômenos, de forma a contrabalançar a tendência, natural em todas as gerações, de ter apenas como guia as inquietações, esperanças, e sonhos (desfeitos ou não), do presente. Nesse sentido, e abrangendo sobretudo a História de Portugal, importa recorrer à visão historiográfica de dois especialistas de períodos históricos diferentes, cujas considerações ajudam a contextualizar o fenômeno da desobediência, da rebeldia, do confronto - e a sua interação com as autoridades - ao longo de cada época.

\footnotetext{
* Investigador no Instituto de Ciências Sociais da Universidade de Lisboa (ICS/UL). Doutor em Política Comparada pela University of Bath, possui pós-doutoramento na Harvard University. <jpzuquete@gmail.com><dados biográficos/biographic data>
} 
$* * *$

António Manuel Hespanha (Coimbra, 1945) é Professor Catedrático jubilado da Faculdade de Direito da Universidade Nova de Lisboa, e Investigador Honorário do Instituto de Ciências Sociais da Universidade de Lisboa. Professor ou investigador visitante em várias instituições universitárias portuguesas e estrangeiras, sendo regularmente Professor Convidado em Universidades Brasileiras. Para além de numerosa colaboração dispersa em jornais e revistas especializadas, é autor, entre outros livros influentes, de Cultura Jurídica Europeia. Sintese de um milénio, 1996 (ed. italiana Bologna, 2000; edição espanhola Madrid, 2002; edição brasileira, 2005). Especialista da Época Moderna, Hespanha escreveu também "Nas vésperas do Leviathan," sobre as instituições e o poder político em Portugal desde o século XVI ao final do século XVIII. A conversa com o historiador incidiu exatamente sobre o Antigo Regime e sobre as manifestações de resistência - populares ou das elites - aos poderes estabelecidos nesse período histórico, e de que maneira é que a autoridade suprema, o poder régio, as enfrentava e reprimia.

- Quais foram, no Antigo Regime, as principais manifestações de Resistência aos poderes por parte quer da Nobreza, quer do Povo?

- Generalizando, inclino-me a responder que, da parte de todos os estratos sociais, a forma mais quotidiana, sustentada e difundida de resistência foi a resistência passiva, ignorando ordens reais, entravandoas com petições, requerimentos e representações burocráticas, discutindo a jurisdição dos magistrados reais e invocando foros especiais, argumentando com privilégios e isenções. $\mathrm{Ou}$, pura e simplesmente, calando-se, escondendo-se, simulando outra identidade ou fugindo. Logo a seguir, quando a confrontação se tornava aberta, usavam a via judicial, sobretudo aqueles que tinham meios para sustentar os litígios, pagando as custas, os advogados e mais uma outra peita aos que deviam decidir. Nos meios populares, a revolta de Antigo Regime - desde a assuada, a "volta em juízo", as "alterações", os tumultos. Tinham a sua liturgia: sinos a rebate, assalto das casas das autoridades locais, nomeadamente dos de fora da terra, queima dos cartórios e, mais tarde, dos registos da fazenda. Isto era muito menos frequente nos estados superiores, pois, neste caso, arriscava-se uma resposta dura por parte das autoridades, sem que se pudesse invocar a rusticidade dos revoltados. 
De vez em quando, qualquer dos braços do reino recorria às cortes. Mas estas reuniões ocorriam muito raramente, sendo as respostas do rei normalmente vagas.

- Nos seus estudos você se refere também uma forma mais "sutil" de Resistência. Pode especificar?

- Refiro-me, justamente, às formas passivas de resistência, como a mentira, a fuga, a chicana burocrática, procedimentos que eram (e continuam a ser) cotidianos e, num sistema políticoadministrativo com pouca informação sobre o território e os homens - mesmo sobre as jurisdições e o direito -, era também muito eficaz.

- De que forma é que a autoridade régia - perante manifestações de Resistência - era imposta? E nas colônias o mecanismo era semelhante?

- As respostas eram as correspondentes aos processos usados.

Mas as medidas de constrangimento eram pouco eficazes. Faltavam extensões periféricas do centro, era difícil e moroso vencer os espaços, faltavam meios logísticos para impor a ordem do centro - oficiais, cadeias, levas de presos -, a informação era escassa. A partir dos meados do séc. XVIII, nota-se um grande esforço para superar isto. Pedem-se informações sobre o território, a população, as estradas, a riqueza local. Mas, em pleno séc. XIX, ainda havia muitas lacunas nestes domínios. Em todo o caso, os finais do séc. XVIII e as primeiras décadas do séc. XIX conhecem muitas iniciativas para colher, sistematizar e difundir a informação básica para o governo central. A situação nas colônias é semelhante, mas agravada pela distância e pela extensão e braveza do território.

- Em que consistia o crime de lesa-majestade - e quando é que foi substituído nos códigos legislativos de Portugal?

- O crime de lesa-majestade tinha uma grande extensão no Antigo Regime. Abrangia a ofensa aos valores supremos da comunidade, religiosos (lesa majestade de primeira cabeça) ou temporais (lesa majestade de segunda cabeça), incluindo ofensas ao rei e sua família, aos oficiais reais ou a direitos exclusivos do rei, como a moeda. Era, para além disso, um crime que, pela sua gravidade, reclamava uma punição 
espetacular e imediata. Isto fazia com que, paradoxalmente com a sua gravidade, se simplificasse e prova e a formalidade processual. Com o liberalismo, há um novo entendimento dos valores protegidos. O crime - agora renomeado, como traição - deixa de se entender como ofensa pessoal ao rei, passando a ser tido como um atentado supremo à ordem social, agora laicizada. Estas mudanças de sentido explicam o seu novo regime, estabelecido nos novos códigos penas (Brasil, 1830; Portugal, 1837 e 1852).

Ernesto Castro Leal (Porto, 1957) é professor associado da Faculdade de Letras da Universidade de Lisboa, e Investigador do Centro de História da Universidade de Lisboa. Especialista da História Contemporânea de Portugal, particularmente da História do Republicanismo, nas suas várias dimensões, Castro Leal tem publicado inúmeros estudos relativos à História das Ideias, História Política, e Biográfica. Entre várias obras individuais, e trabalhos de edição, destaca-se, por exemplo, "Partidos e Programas. O campo partidário republicano português 1910-1926". E foi sobre essa primeira experiência republicana em Portugal, marcada pela instabilidade política e por inúmeros episódios de resistência aos novos poderes, que Ernesto Castro Leal se debruçou nesta entrevista.

- De que maneira é que a 'resistência' ao novo regime (República) se manifestou no Portugal do início do século XX? Pode falar sobre os seus momentos/episódios mais marcantes, violentos, ou não?

A 'resistência' ao regime político parlamentarista da I República Portuguesa (1910-1926) recobriu uma variedade de expressões, quer dentro do campo político republicano, quer dentro dos campos políticos monárquicos e católicos, quer dentro do campo sindicalista abordado na segunda pergunta.

Durante a primeira grande fase do regime (1910-1919) devese assinalar, no campo republicano, o 'movimento das espadas' de 21 de janeiro de 1915, que colocou no poder o Governo do general Joaquim Pimenta de Castro, tendo em vista uma reorientação política moderada do sistema de governo parlamentar face ao radicalismo dos 
'democráticos' (Partido Republicano Português), tutelados por Afonso Costa, apesar da tentativa pacificadora de dois Governos 'democráticos' de Bernardino Machado (9-2-1914 a 12-12-1914), vindo a terminar na muito violenta revolução de 14 de maio de 1915 , que repôs no poder os 'democráticos'; o golpe militar de 5 de dezembro de 1917, que, através da governação de Sidónio Pais, visou uma refundação política da República por meio de um sistema de governo presidencial ('República Nova'), tendo terminado com o assassinato de Sidónio Pais (o 'Presidente-Rei', na leitura político-poética de Fernando Pessoa), na noite de 14 de dezembro de 1918, dentro da Estação ferroviária do Rossio, em Lisboa; as movimentações subversivas de António Machado Santos (o 'herói militar' da revolução de 5 de outubro de 1910) em abril de 1913 e em janeiro de 1914 (contra o Governo de Afonso Costa), em 13 de dezembro de 1916 (contra o Governo da 'União Sagrada' entre 'democráticos' e 'evolucionistas'), acabando preso, e em 5 de dezembro de 1917 participou ativamente no golpe militar de Sidónio Pais.

No campo monárquico sobressaiu a ação contrarrevolucionária violenta desenvolvida através das 'incursões' militares dirigidas pelo oficial do Exército Henrique de Paiva Couceiro, a partir da Galiza, em outubro de 1911 e em Julho de 1912, e a tentativa de criar a 'monarquia do Norte' em janeiro de 1919, com a proclamação da restauração monárquica na cidade do Porto por Paiva Couceiro (19 de janeiro) e a falhada restauração monárquica em Lisboa comandada por Aires de Ornelas (23-24 de janeiro), tendo havido, em várias localidades, fortes confrontos com os revoltosos monárquicos.

No campo católico, a 'guerra religiosa' (corte de relações com a Santa Sé, expulsão e ódio principal aos jesuítas, prisões e exílio de padres, desterro de bispos, ocupação de instalações religiosas, etc.) desenvolveuse por meio das medidas repressivas anticongreganistas e anticlericais do Governo Provisório da República, marcadas por radicalismo laicista do Estado e secularizador da sociedade, com vista a incrementar uma religião cívica republicana (com algumas aproximações à religião civil de Rousseau), reduzindo-se muito o espaço público da Igreja Católica, o que teria consagração jurídico-política na Lei da Separação do Estado das Igrejas (20 de abril de 1911) e na sua execução radicalista, afastando a versão moderada, inspirada na Lei da Separação brasileira (7 de janeiro de 1890), que o deputado republicano constituinte Eduardo de Abreu tinha defendido. Em 1913, o programa do Partido Republicano Evolucionista, chefiado por António José de Almeida, já incorporava a 
necessidade de uma revisão de sentido moderado da Lei da Separação de 1911 e, durante a República Nova, iniciou-se um processo, continuado a partir de 1919, de restabelecimento das relações entre o Estado e a Igreja Católica, mas, em alguns momentos, manifestaram-se novos afrontamentos da responsabilidade de Governos republicanos mais radicais e laicistas.

Na segunda grande fase do regime (1919-1926), o acontecimento trágico mais violento decorreu na 'noite sangrenta' de 19 de outubro de 1921, com os assassinatos cometidos por soldados da Guarda Nacional Republicana e por praças do Exército e da Marinha (comandados pelo cabo Abel Olímpio, 'o dente de ouro') contra o advogado António Granjo (presidente do Governo republicano liberal em exercício), o almirante António Machado Santos (considerado o 'fundador' da República), o capitão de mar e guerra José Carlos da Maia (amigo muito próximo de Machado Santos e comandante das forças navais revoltosas na revolução de 5 de outubro), o capitão de fragata Carlos Freitas da Silva e o coronel do Exército Alexandre Botelho de Vasconcelos. Podem considerar-se esses atos horrorosos uma espécie de 'republicanicídio', estando ainda hoje envolta em obscuridade toda essa barbaridade decorrente do clima político e social violento que cresceu desde finais de 1919.

Perante essa situação, alguns governos republicanos, entre 1919 e 1922, cometeram o enorme erro de alargar os quadros e a capacidade militar ofensiva (incluindo com artilharia) da Guarda Nacional Republicana, acreditando na eficácia de uma 'guarda pretoriana' face ao progressivo distanciamento do Exército do regime. A primeira grande tentativa do corpo militar profissional para derrubar a I República Portuguesa ocorreu no dia 18 de abril de 1925 e, a partir de novembro desse ano, a teia nacional conspirativa civil-militar expandiu-se até ao vitorioso golpe militar de 28 de maio de 1926 . Houve um relativo apaziguamento no campo católico e no campo monárquico, que passaram a ter um pouco mais de representação no Parlamento, participando ativamente nos debates parlamentares, devendo salientar-se a convergência institucional do Presidente da República António José de Almeida (1919-1923) e do Cardeal-Patriarca D. António Mendes Belo para a reposição definitiva das relações entre o Estado e a Igreja Católica, dentro de um ambiente mais tolerante.

- A Primeira República lidou com constantes mobilizações de rua, manifestações de massas (a maior parte delas organizadas pelo 
movimento operário), greves (Afonso Costa chegou a ser conhecido como o 'racha-sindicalistas'), saques, assassinatos de políticos, e protestos de toda a ordem. De que forma é que os sucessivos governos (39 governos, de 1910 a 1926) lidaram com esta situação? E este contexto ajuda a explicar o pendor mais autoritário desta primeira experiência republicana em Portugal?

- A crença numa República social rapidamente se desvaneceu nos meios operários, pouco depois da revolução republicana, como está bem expresso através da ação do personagem Alfredo Reinegro no romance Os Reinegros (1945) de Alves Redol, cujo tempo narrativo se desenrola durante a transição da Monarquia para a República. A contestação e a violência operária continuou ao longo da I República Portuguesa, apesar de, nos dois primeiros governos de 1919, através do ministro do Trabalho Augusto Dias da Silva (socialista) se legislar, finalmente, o seguro social obrigatório (doença, velhice, acidentes de trabalho) e a semana de 48 horas para a maioria dos trabalhadores e de 42 horas para os bancários e empregados de escritório. Permaneciam redes secretas ou semi-secretas de antigos carbonários que se envolviam também no boicote a greves. Nos anos 20, houve uma radicalização anarquista com a criação da Legião Vermelha, responsável por vários atentados. A partir de 1921, os movimentos revolucionários_militares aumentaram, quer de republicanos radicais, quer de republicanos conservadores, com fraturas importantes dentro da instituição militar. A dificuldade dos governos republicanos deterem em exclusivo o monopólio formal da violência, através das instituições legais, e a pulverização partidária do campo político republicano - mais ampla do que na primeira grande fase do regime - foram fatores que propiciaram governos fracos e pouco duradouros. A hegemonia no pensamento político republicano da ideia e da prática de uma 'República para os republicanos', apesar das correções institucionalistas desenvolvidas no período da Primeira Guerra Mundial e após a República Nova/Sidonismo, dificultou a consagração de uma 'República para os portugueses'. Impôsse, portanto, uma visão geral mais próxima de uma República jacobina, oligárquica e autoritária (sem consagração do sufrágio universal e com um partido dominante) do que de uma República democrática moderna (com sufrágio universal e competição política aberta). Ao longo do regime, em temporalidades diversas, foram definidos os seus principais 'inimigos internos': jesuítas, católicos ultramontanos, monárquicos, sindicalistas, anarquistas, comunistas. 
- Na Primeira República, quais foram, para você, as figuras intelectuais, doutrinadores, ativistas, políticos - que melhor personificaram a ideia de 'resistência' ao poder. E por quê?

- Existiram vários tipos de 'resistência' ao poder republicano na versão dominante jacobina e revolucionária que foram protagonizadas por figuras relevantes, das quais se seleciona as seguintes: no campo católico, D. António Barroso (bispo do Porto), a capacidade negocial de D. António Mendes Belo (Cardeal Patriarca de Lisboa) e o ativismo de António de Oliveira Salazar; no campo republicano moderado, José Pereira de Sampaio (Bruno), António José de Almeida e António Granjo; no campo republicano reformista radical, António Machado Santos e José Pinto de Macedo; no campo republicano presidencialista, Sidónio Pais e Martinho Nobre de Melo; no campo monárquico, Henrique de Paiva Couceiro, Aires de Ornelas e António Sardinha; no campo militar republicano reformista conservador, generais Joaquim Pimenta de Castro e Manuel Gomes da Costa e capitão de fragata Filomeno da Câmara; no campo sindicalista e, por algum tempo bolchevista, José Carlos Rates e Manuel Ribeiro; no campo da cultura, José de Almada Negreiros e Fernando Pessoa.

- Portugal, portanto, não é (ou não foi nesse período) um país de 'brandos costumes'?

Se tivermos uma visão global do tempo contemporâneo português, entre 1807 (primeira invasão napoleónica em Portugal) e 1926 (golpe militar contra a I República Portuguesa), o certo é que a violência política, militar e social, por vezes de grande intensidade, manifestou-se, recorrentemente, em vários momentos da vida portuguesa: 1807-1811 (ambiente das invasões napoleônicas); 1820-1851 (primeiro liberalismo, com as revoluções de 1820 e de 1836 , a restauração do absolutismo com D. Miguel em 1828-1834, as relevantes guerras civis de 1832-1834 e de 1847 ou a revolta nortenha da Maria da Fonte em 1846); 1908 (regicídio do rei D. Carlos e do príncipe Luís Filipe); 1910-1926 (ambiente da I República Portuguesa, marcado por fortes características de 'guerra civil intermitente', com golpes militares, sendo os mais violentos os de 5 de outubro de 1910 e de 14 de maio de 1915, assassinatos, por exemplo, do 'democrático' visconde da Ribeira Brava e do Presidente da República Sidónio Pais em 1918 e de António Granjo, António Machado Santos ou José Carlos da Maia na 'noite sangrenta' de 1921), 
de revoltas sociais urbanas e rurais (contra a carestia de vida, contra a fome ou contra as condições de trabalho). Por outro lado, a capacidade de negociação e de ajustamento social e político também deve ser valorizada: o longo período da Regeneração (1851-1890). A matriz revolucionária e carbonária da revolução republicana de 5 de outubro de 1910, com a polarização, por vezes forte, de áreas concorrenciais dentro do campo político republicano, o envolvimento (com grande deficiência de preparação militar e de recursos financeiros) de Portugal nas frentes africana e europeia da Primeira Guerra Mundial ou a crise financeira e a inflação entre 1914-1924, foram circunstâncias assinaláveis para a permanente instabilidade política, militar e social durante a I República Portuguesa. A possibilidade regeneracionista da República em 19241925 acabou mal sucedida e abriu a possibilidade da convergência das várias direitas políticas, sociais e culturais que impuseram o golpe militar de 28 de maio de 1926, institucionalizado na atribulada Ditadura Militar (1926-1932), seguindo-se a longa Ditadura do Estado Novo (1933-1974). O ‘mito do Estado' e o 'mito da Revolução' foram dois importantes mitos políticos presentes na cultura política portuguesa contemporânea desde 1820 até 1974, desvalorizando-se quase sempre a construção de uma vigorosa sociedade civil, com as suas diversas instituições, apesar, por exemplo, da permanente retórica política sobre a antiga 'tradição municipalista'.

\footnotetext{
Autor/Author:

JosÉ PEDRo ZÚQUETE <jpzuquete@gmail.com>

- Investigador no Instituto de Ciências Sociais da Universidade de Lisboa (ICS/UL). Tem experiência na área de História Contemporânea e Ciência Política, atuando principalmente nas pesquisas sobre nacionalismo, assim como aos estudos sobre antiglobalização e geopolítica. Doutor em Política Comparada pela University of Bath, possui pós-doutoramento na Harvard University. Faz parte da rede europeia COST sobre populismo. Autor de vários artigos científicos, publicou os livros Missionary Politics in Contemporary Europe (Syracuse University Press, 2007) e The Struggle for the World (Stanford University Press, 2010). Coeditou também A vida como um filme (Leya, 2011) e Grandes Chefes na História de Portugal (Leya, 2013), além de ter colaborado na obra Dimensões do poder: história, política e relações internacionais (EdiPUCRS, 2015).

- Researcher at the Institute of Social Sciences, Universidade de Lisboa (ICS/UL), Portugal. He has experience in Contemporary History and Political Science, working mainly on themes such as Nationalism, Anti-globalization and Geopolitics. PhD in Comparative Politics (University of Bath, UK), he was also a post-doctoral fellow at Harvard University. Member of the European COST network on populism. Author of several scientific papers and books, among which stand out Missionary Politics in Contemporary Europe (Syracuse University Press, 2007) and The Struggle for the World (Stanford University Press, 2010). He is also co-editor of A Vida como um Filme (Leya, 2011) and Grandes Chefes na História de Portugal (Leya, 2013), and has collaborated to Dimensões do Poder: História, Política e Relações Internacionais (EdiPUCRS, 2015).
} 